\title{
Copper recovery by slurry electrolysis using ionic liquids from waste printed circuit boards
}

\author{
Sarwar M.T. ${ }^{1 *}$, HanHui Z. ${ }^{1 *}$, Yang J. ${ }^{2}$, Maqbool A. ${ }^{3}$, Khan R.K.M. ${ }^{4}$ and Ullah B. ${ }^{5}$ \\ ${ }^{1}$ School of Environmental Sciences and Spatial Informatics, China University of Mining and Technology, Xuzhou, 221116, P.R. China \\ ${ }^{2}$ Nanjing Research Institute of Environmental Science, Nanjing, 210042, P.R. China \\ ${ }^{3}$ CAS Key Laboratory of Soil Environment and Pollution Remediation, Institute of Soil Science, Chinese Academy of Sciences, Nanjing, \\ P.R. China \\ ${ }^{4}$ School of Resources and Geosciences, China University of Mining and Technology, Xuzhou, 221116, P.R. China \\ ${ }^{5}$ Schoolof Resources and Safety Engineering, Central South University, Changsha, 410010, P.R. China \\ Received: 22/12/2020, Accepted: 18/03/2021, Available online: 07/06/2021 \\ *to whom all correspondence should be addressed: e-mail: tariqsarwar98@yahoo.com \\ https://doi.org/10.30955/gnj.003490
}

\section{Graphical abstract}

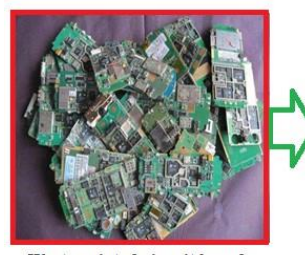

Waste printed circuit boards
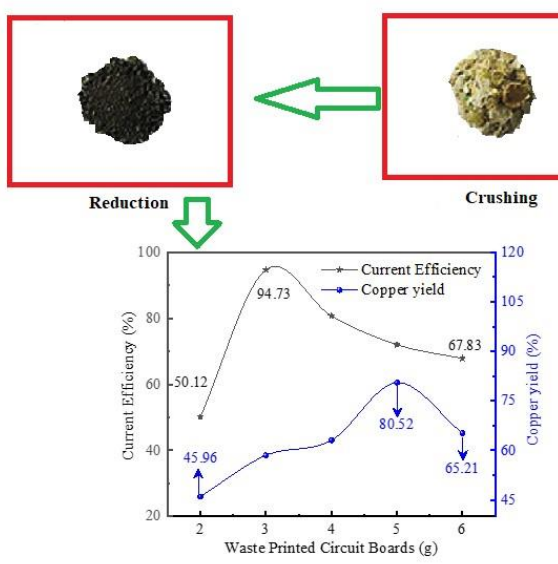

Copper recovery from waste printed circuit boards

\begin{abstract}
The regulatory framework of heavy metal pollution associated with electronic waste is prevalent all over the world. As a result of technological advancement and change in consumer patterns, the life span of electrical and electronic products has been shortened. This has contributed to the emergence of massive amounts of electronic waste that needs to be handled. With the exponential growth of the telecommunications sector, the recycling of useful resources from electronic waste devices, especially mobile phones, is of great significance. Besides, the presence of valuable metals enables the recycling of electronic waste potentially appealing. In this research, numerous types of ionic liquids like Butyl
\end{abstract} methylimidazolium hexafluorophosphate $\left[\mathrm{Bmim}_{[}\left[\mathrm{PF}_{6}\right]\right.$, Butyl methylimidazolium chloride [Bmim][Cl], Ethyl methylimidazolium chloride $[\mathrm{Emim}][\mathrm{Cl}]$ and Butyl methylimidazolium tetrafluoroborate $[\mathrm{Bmim}]\left[\mathrm{BF}_{4}\right]$ were used to analyze the copper leaching behavior of electronic mobile handset devices. Several influential aspects on the leaching efficiency of copper including different types of ionic liquid, temperature and leaching time have been examined. The findings showed $\left[\mathrm{Bmim}_{[}\left[\mathrm{PF}_{6}\right]\right.$ and [Emim] $[\mathrm{Cl}]$ were better ionic liquids in appropriate conditions for high copper leaching rates.

Keywords: copper metal leaching, different ionic liquids, electronic waste, slurry electrolysis

\section{Introduction}

As a conventional electronic waste, the abundant production of cell phone waste in recent years has demonstrated that it is highly essential to recycle useful materials from mobile phone waste and in the meantime to monitor the emission of dangerous materials (Sarwar et al., 2020; Qiu et al., 2020). Effective disposal and recycling of electronic waste are of great significance for the adaptive re-use of useful materials including precious metals, zinc, copper, etc. and for eliminating emissions of hazardous components like lead and cadmium (Delcea et al., 2020). Printed circuit boards include numerous procurement metals as gold, platinum, etc and base metals such as copper, aluminum and so on as the key frames of electronic devices (Miner et al., 2020; Holgersson et al., 2018). Consequently, effective manufacturing of waste printed circuit boards is an immediate requirement that promotes the recycling and re-use of useful materials (Adamo et al., 2019).

Electrolysis treatment of waste printed circuit boards primarily focuses on the electrodeposition of metals, which reported in a few surveys and cases (Chu et al., 2015). The complete removal of metals and non-metals from waste printed circuit boards was obtained by slurry 
electrolysis. The metal and non-metal removal percentage achieved $97 \%$ with a copper recovery of almost $99 \%$ (Yang et al., 2018).

Slurry electrolysis includes electrowinning, solvent purification, leaching, and electrodeposition in a single operation, consisting of cathodic (electrodeposition) and anodic (dissolution of metal) sections (Chu et al., 2015). Effective recovery from CPU sockets of copper and gold by slurry electrolysis. Purity and recovery of copper were up to $98 \%$ and $96 \%$, respectively (Li et al., 2019).

Recovered high purity copper cathode using ammonia sulfate solution printed circuit boards (Sun et al., 2015). Copper was eventually recovered from electrodepostion in the sulfate systems after leaching and solvent extraction. A simultaneous electro-leaching process carried out the direct copper recovery from the powder of waste printed circuit board. Apparent recovery of $96 \%$ of copper was achieved at $25{ }^{\circ} \mathrm{C}$ (Choubey et al., 2015).

Ionic liquids (ILS) are usually based on cations and anions, which possess a low vapor pressure, thermal stability and broad electrochemical window, high conductivity, and wide range of liquid temperatures, non-volatilization, etc (Muhammad Tariq et al., 2020; Singh and Savoy, 2020). A potential study was carried out to dissolve epoxy bromine resins with printed circuit boards using [EMIM+][BF4-] ionic liquid to recover copper foils and glass fibers. The full separating of waste printed circuit boards was obtained by processing copper and glass fibers at a $260{ }^{\circ} \mathrm{C}$ temperature (Zhu et al., 2012). The leaching of copper tendencies were studied present in waste printed circuit boards by different ionic liquids and also optimum situations produced about 98\% copper leaching efficiency (D. Zhang et al., 2018). Also, the recovery output of metals has been tested with different types of ionic liquid and the results of numerous operating aspects have been calculated from waste printed circuit boards (Chen et al., 2015; Gu et al., 2019). Chemical reagent [ $\left.\mathrm{BSO}_{3} \mathrm{HPy}\right]\left[\mathrm{HSO}_{4}\right]$ was used in slurry electrolysis process to extract copper from waste printed circuit boards. The optimum standard was achieved with a recovery rate, purity, current performance and copper powder particle size of $90 \%, 81 \%$, $70 \%$, and $2.30 \mu \mathrm{m}$ (Y. Zhang et al., 2018).

Despite some novel discoveries in the recovery of metals from waste printed circuit boards using ionic liquid, the processing of copper has not adequate using slurry electrolysis from waste phones. It is essential for effective recovery of copper to evaluate the appropriate kind of ionic liquids. This study therefore used waste mobile phones of similar form as a target entity for analysis and as leaching solvent used $[\mathrm{Bmim}][\mathrm{Cl}]$, $\left[\mathrm{Bmim}^{-}\left[\mathrm{BF}_{4}\right]\right.$, [Bmim] $\left[\mathrm{PF}_{6}\right],[\mathrm{Emim}][\mathrm{Cl}]$ ionic liquids. Different influential operating aspects on the performance of copper leaching including various types of ionic liquid, leaching time and temperature were analyzed.

\section{Materials and methods}

\subsection{Materials and reagents}

All major reagents such as $\mathrm{HNO}_{3}$ chemical with purity $\mathrm{AR}, 65.0-68.0 \%, \mathrm{HClO} 4$ chemical with purity AR,70.0-
72.0\%, $\mathrm{H}_{2} \mathrm{SO}_{4}$ purity $\mathrm{AR}, 95.0-98.0 \%, \mathrm{HCl}$ urity $\mathrm{AR}, 36.0-$ $38.0 \%$ were purchased from Shanghai Susong Chemical factory. $\mathrm{CuSO}_{4} \cdot 5 \mathrm{H}_{2} \mathrm{O}, \mathrm{NaCl}, \mathrm{H}_{2} \mathrm{O}_{2}$ and $\mathrm{C}_{6} \mathrm{H}_{5} \mathrm{~N}_{3}$ were purchased from Shanghai Guangnuo Chemical factory. $\mathrm{C}_{6} \mathrm{H}_{11} \mathrm{CIN}_{2}$ chemical with purity $\mathrm{AR}, 99 \%$ and $\mathrm{C}_{8} \mathrm{H}_{15} \mathrm{CIN}_{2}$ chemical with purity $A R, 99 \%$ were purchased from Lanzhou Institute of Materialization factory. $\mathrm{C}_{8} \mathrm{H}_{15} \mathrm{PF}_{6} \mathrm{~N}_{2}$ with purity of $\mathrm{AR}, 99 \%$ and $\mathrm{C}_{8} \mathrm{H}_{15} \mathrm{BF}_{4} \mathrm{~N}_{2}$ chemical with purity of $A R, 99 \%$ were purchased from the Shanghai Chengjie Chemical company. [Bmim] $[\mathrm{Cl}],[\mathrm{Bmim}]\left[\mathrm{BF}_{4}\right],[\mathrm{Bmim}]\left[\mathrm{PF}_{6}\right]$ and $[$ Emim $][\mathrm{Cl}]$ ionic liquids were used.

In order towards unify test conditions, $30 \mathrm{Kg}$ of same types of waste mobile phone circuit board materials were purchased in this study. Electric gears including USB ports, camera and microphone have been well separated from cell phone frames. Then, used cutting grinder to crushed well of waste boards upto the size of $0.9 \mathrm{~mm}$. The original waste printed circuit boards contained $89.89 \%, 1.91 \%$, $6.74 \%, 1.07 \%$, and $0.39 \%$ of copper, iron, zinc, platinum and aluminum.

\subsection{Experimental procedure}

In order to examine the influence of different factors on the performance of leaching of copper by using various types of ionic liquid, every kind of ionic liquid was used to prepare a specified solution quantity at certain temperatures. For $\left(\mathrm{Bmim}_{\mathrm{PF}}-\mathrm{Cu}_{(}\left(\mathrm{PF}_{6}\right)_{2}\right.$ ionic liquid solution preparation, first $5 \mathrm{ml}$ ion liquid of $\left[\mathrm{Bmim}^{-}\left[\mathrm{PF}_{6}\right]\right.$ was put in 5 beakers, respectively. Five beakers were put in the water bath and feed materials with a weight of $1 \mathrm{~g}, 2 \mathrm{~g}, 3$ $\mathrm{g}, 4 \mathrm{~g}$, and $5 \mathrm{~g}$ were fed into beakers with a $25^{\circ} \mathrm{C}$ temperature and $60 \mathrm{~min}$ of heating time. The plate was washed for $3 \mathrm{~min}$ with $13 \%$ concenteration of hydrochloric acid (diluted) and was continually cleaned for further $10 \mathrm{~min}$ with alcohol (absolute). Plate was eventually clean rinsed and for further used oven dried it.

Copper recovery rate is calculated as shown in Eq. (1).

$$
\text { Recovery Rate }(\%)=\frac{x}{x_{1}} \times 100
$$

Where $X$ is the recovery amount in gram (g); the mass of the metal recovered after electrolysis reaction; $X_{1}$ is the initial content of metal in waste printed circuit boards.

The current efficiency calculation method of copper is as shown in Eq. (2)

$$
\eta_{\mathrm{Cu}}=\frac{Y_{1}}{Y_{2}}
$$

Where $Y_{1}$ is the mass of copper obtained in the actual test in $g_{;} Y_{2}$ is the mass of copper theoretically calculated according to Faraday's law in $g$; The formula for calculating $Y_{2}$ is in Eq. (3):

$$
Y_{2}=t \times K \times I
$$

Where $t$ is the time of energization (h); $K$ is electrochemical coefficient $(\mathrm{g} / \mathrm{h} * \mathrm{~A}) ; l$ is the intensity of current (A); the value of copper electrochemical coefficient is 1.18 $\mathrm{g} / \mathrm{h} * \mathrm{~A}$. 


\section{Results and discussion}

\subsection{Influence of time on recovery rate of copper}

It's visible from Figure 1 The copper recovery rate rate rises with the reaction time and there is no intervention point for the recovery of copper. So if the time varies from $1 \mathrm{~h}$ to $5 \mathrm{~h}$, the copper recovery rate obviously changes from around $50 \%$ to $73 \%$.

On the other hand, the current efficiency showed an inflection point during the entire reaction phase. When the time shifted from 1 to 3 hours, current productivity rose from around $47 \%$ to $87 \%$. The current efficiency declined to around $56 \%$ percent as the reaction proceeded. Therefore the current efficiency achieved the optimum value when the reaction was conducted over 3 hours.

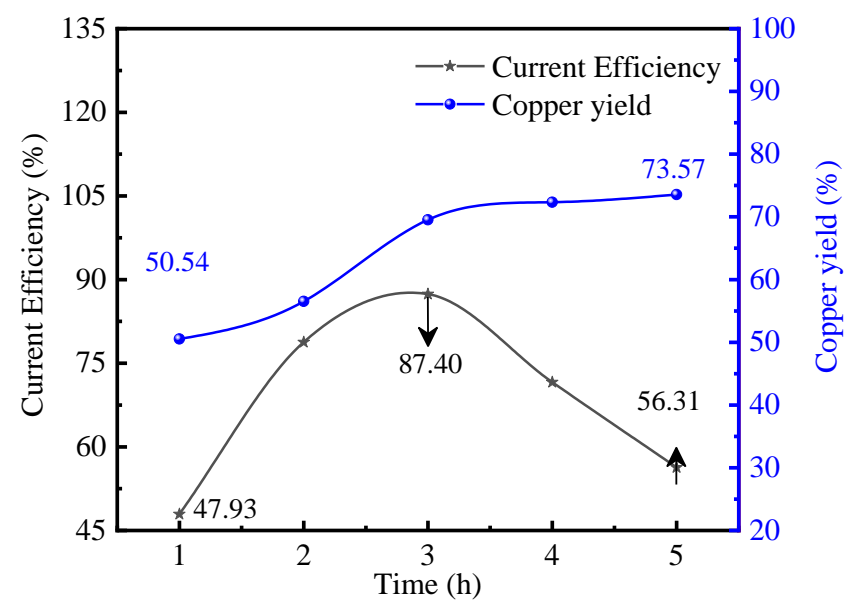

Figure 1. Influence of time on copper recovery and current efficiency

According to the study, the anode is quickly oxidized when the electrolysis process is just underway, and the reaction is intensive enough that a lot of metal is extinguished. Metal cation is continuously given for the entire anodizing phase for the reaction, so that the cathode decrease reaction is fast and the metal is deposited electrolytically in large amounts and the recovery speed becomes increase. As the reaction process continues, the anodyne reaction promotes metal laxation at a much slower rate than the cathode redox reaction, which supports side reactions mainly due to the apparent process of hydrogen transformation. Other metals are deposited together in the electrolyte copper metal, which affects metallic copper recovery and also reduces electrical energy utilization.

\subsection{Influence of ionic liquids}

Leaching efficiency of copper influence by four different ionic liquids which is seen in Figure 2. The findings revealed that prevalence of pure copper leaching was effectively a linear increase of leaching time with different ionic liquids.

Generally, the most significant copper leaching influence level of lonic liquids was (Bmim-BF4) $<(B$ mim $-\mathrm{Cl})<($ Emim$\mathrm{Cl})<(\mathrm{Bmim}-\mathrm{PF} 6)$. Conclude, the overall leaching rate of copper $10.3209 \%$ was obtained with $50^{\circ} \mathrm{C}$ of leaching temperature and time of 120 min by using $B m i m\left[\mathrm{PF}_{6}\right]$ as solution. Ionic liquids have a leaching effect on metallic copper because these four ionic liquids are an acidic liquid. As a new "Green Solvent," it has also been used in metal minerals to leach metals.

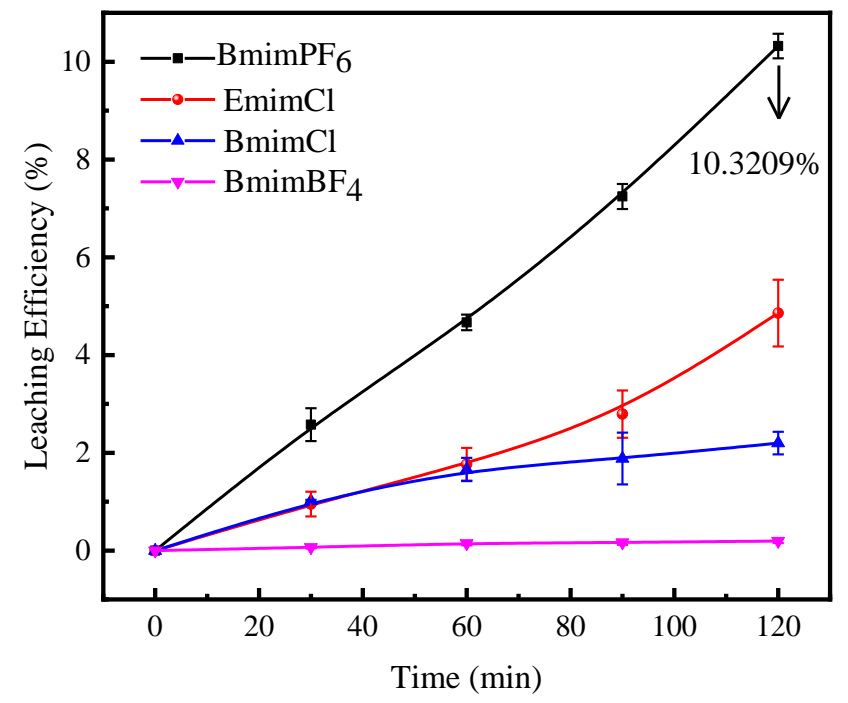

Figure 2. Influence of different ionic liquids on leaching of copper efficiency

\subsection{Influence of waste printed circuit boards dosage on copper recovery rate}

Figure 3 indicates that during the test the highest inflection point occurs for the copper recovery rate. When the Waste Printed Circuit Boards feed volume is $5 \mathrm{~g}$, the recovery rate for copper exceeds $80 \%$. With the feed rate continuing to grow, however, the recovery rate is reduced to $65 \%$ but copper relative recovery rate is $45 \%$. The feedstock quantity remains a factor in improving the copper recovery rate. In comparison with the current efficiency, as the feed rate of Waste Printed Circuit Boards increases from $2 \mathrm{~g}$ to $3 \mathrm{~g}$ Copper real efficiency rises from $50 \%$, to $94 \%$ but when the feeding rate of Waste Printed Circuit Boards continues to rise to $6 \mathrm{~g}$, its current efficiency declines up to $67 \%$.

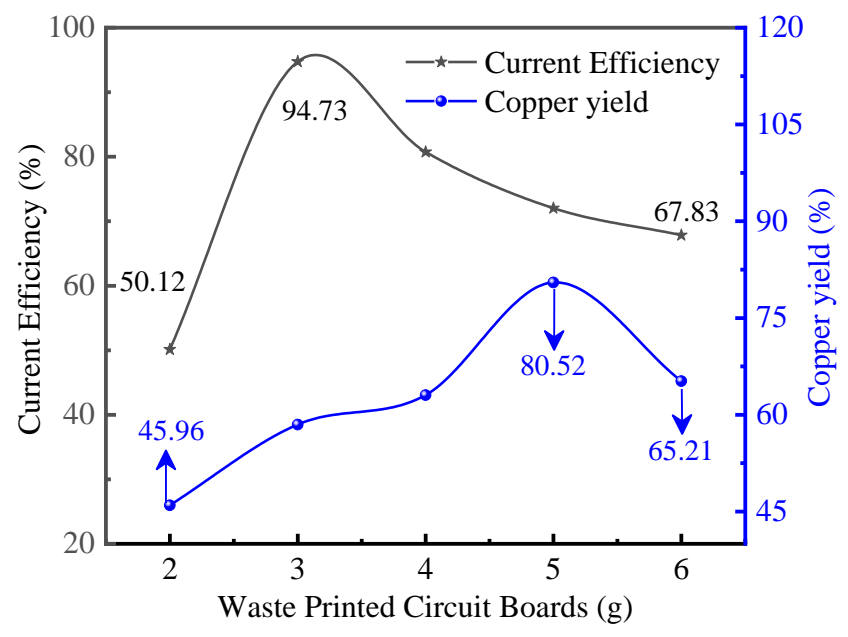

Figure 3. Influence of WPCBs dosage on copper recovery and current efficiency 
The study suggested that the continued addition of Waste Printed Circuit Boards to the electrical process is not conducive when the feed rate for the Waste Printed Circuit Boards rises to a higher concentration. Although the copper content of the raw materials is increased, more mixture of metal or non-metallic impurities affects the electrolysis reaction simultaneously.

\subsection{Influence of time and temperature on $\left[\mathrm{Bmim}^{2}\left[\mathrm{PF}_{6}\right]\right.$ solution}

As revealed in Figure 4, the copper leaching rate for the solution of ionic liquid $[\mathrm{Bmim}]\left[\mathrm{PF}_{6}\right]$ and $50^{\circ} \mathrm{C}$ leaching temperature showed a remarkable rise with the increase of the leaching time. The copper leaching rate was relatively high around $19 \%$ and $22 \%$ for 60 minutes and 120 minutes respectively. In addition, the copper leaching rate also demonstrated a significant rise in the leaching duration at $25^{\circ} \mathrm{C}$ of leaching temperature. The growing trend, however, was less obvious than the $50^{\circ} \mathrm{C}$ temperature. The rate of copper leaching did not display any significant increase in the leaching cycle, if the leaching temperature increased to $100^{\circ} \mathrm{C}$.

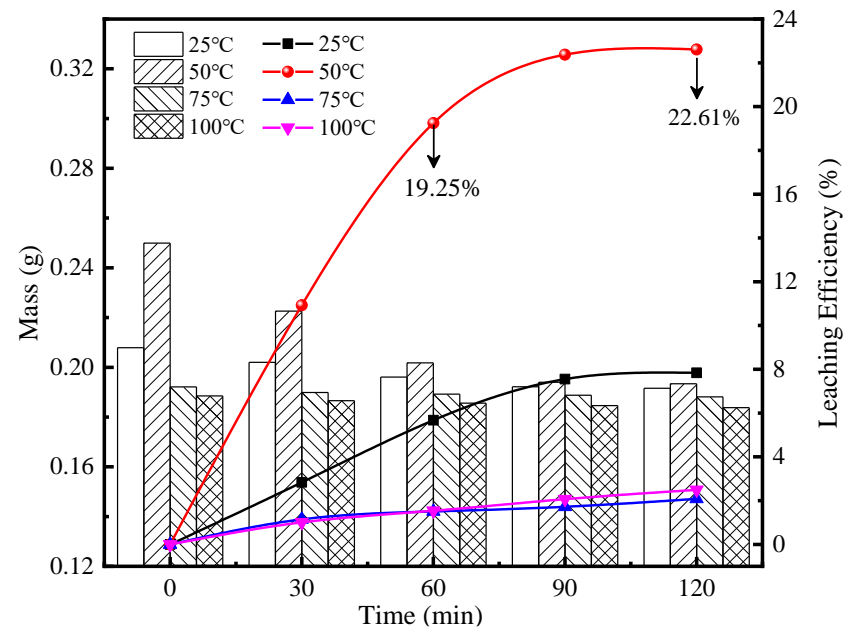

Figure 4. Influence of time and temperatures on copper leaching of $\mathrm{BmimPF}_{6}$

[Bmim] $\left[\mathrm{PF}_{6}\right]$ ionic liquid is highly oxidizable. The proper increase in the leaching temperature can boost [Bmim] $\left[\mathrm{PF}_{6}\right]$ oxidizability.

\subsection{Influence of time and temperature on $\left[\mathrm{Bmim}^{2}\left[\mathrm{BF}_{4}\right]\right.$ solution}

As revealed in Figure 5, with $[\mathrm{Bmim}]\left[\mathrm{BF}_{4}\right]$ solution at $25^{\circ} \mathrm{C}$ leaching temperature with rise in leaching time, the copper leaching rate steadily improved. In fact, the maximum copper leaching rate was reached at $25^{\circ} \mathrm{C}$ and $120 \mathrm{~min}$. The leaching temperature was around $2 \%$. However as the temperature for the leaching rose to $100^{\circ} \mathrm{C}$, leaching rate of copper increased significantly.

The high liquid temperature causes $[\mathrm{Bmim}]\left[\mathrm{BF}_{4}\right]$ to react inactively as a solution. In addition, $\left[\mathrm{Bmim}^{\mathrm{m}}\right]\left[\mathrm{BF}_{4}\right]$ demonstrates solubility with water at average temperature. The mutual solubility of $\left[\mathrm{Bmim}^{2}\left[\mathrm{BF}_{4}\right]\right.$ declines as the leaching temperature increases.

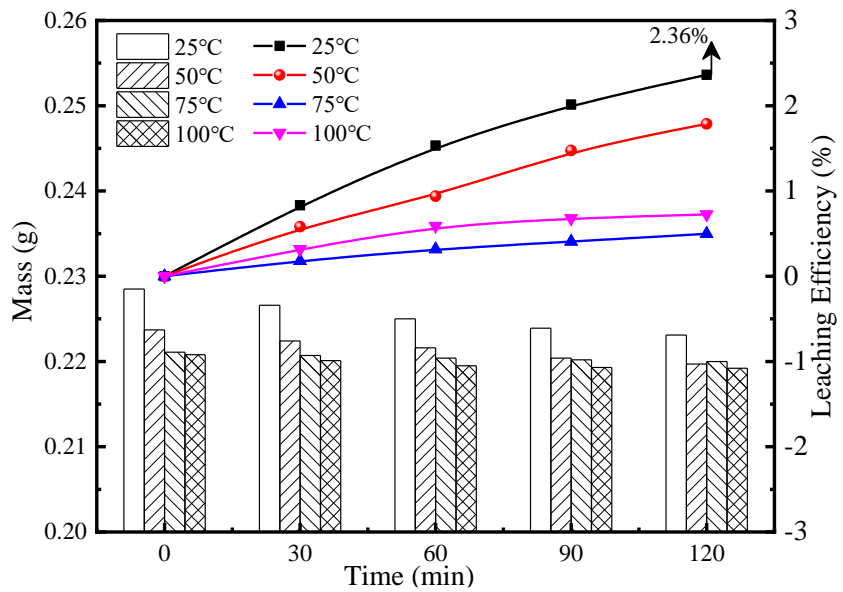

Figure 5. Influence of time and temperatures on copper leaching of $\mathrm{BmimBF}_{4}$

3.6. Influence of time and temperature on [Emim][Cl] solution

As seen in Figure 6, the leaching rate of copper increased steadily as time increased 0 to 60 minutes and at $25^{\circ} \mathrm{C}$ of leaching temperature on solution of $[\mathrm{Emim}][\mathrm{Cl}]$ and appeared to be constant as the leaching period continued to increase. In comparison, leaching efficiency of copper enhanced dramatically by leaching interval at $50^{\circ} \mathrm{C}$ of leaching temperature. In addition, leaching rate of copper was around $9 \%$ and $13 \%$ percent for 60 minutes and 120 minutes. But as the leaching temperature rises to $100^{\circ} \mathrm{C}$, the rate of leaching of copper did not rise considerably as the leaching time rose.

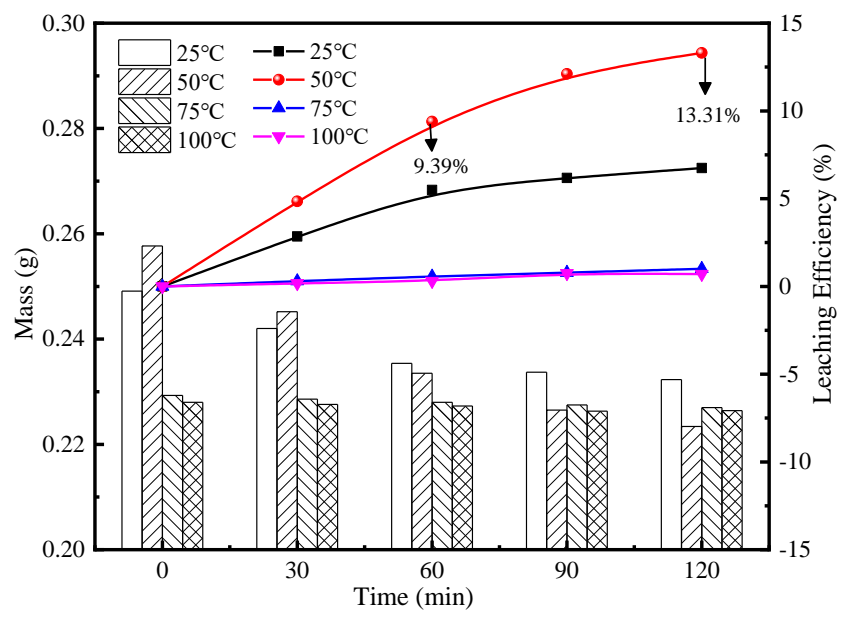

Figure 6. Influence of time and temperatures on copper leaching of $\mathrm{EmimCl}$

The appropriate change of temperature can catalyze and endorse leaching reaction. Although it is difficult to mix oxygen produced by decomposing $\mathrm{H}_{2} \mathrm{O}_{2}$ into ionic liquids when the leaching temperature is too high and then volatilize it out of reaction pot. Oxygen level therefore declines drastically in entire process (ionic liquid), which decreases leaching efficiency of copper and stands unfavorable towards copper oxidation. Briefly, ideal ionic liquid [Emim] $\mathrm{Cl}$ leaching temperature is $50^{\circ} \mathrm{C}$ with a 120 min of leaching rate. 


\subsection{Influence of time and temperature on [Bmim][Cl] solution}

As seen in the Figure 7 , at a leaching temperature of $25^{\circ} \mathrm{C}$ showed a clear rise as the leaching time increased on [Bmim] $[\mathrm{Cl}]$ solution. The copper leaching rate in generally was around $3 \%$ and $4 \%$, and the leaching interval was 60 minutes and 120 minutes. In comparison, the elevated copper leaching rate was not as noticeable at leaching temperature of $50^{\circ} \mathrm{C}$ compared with $25^{\circ} \mathrm{C}$. Likewise, leaching efficiency of copper as leaching temperature rose to $100^{\circ} \mathrm{C}$ did not evidently rise as the leaching time increased.

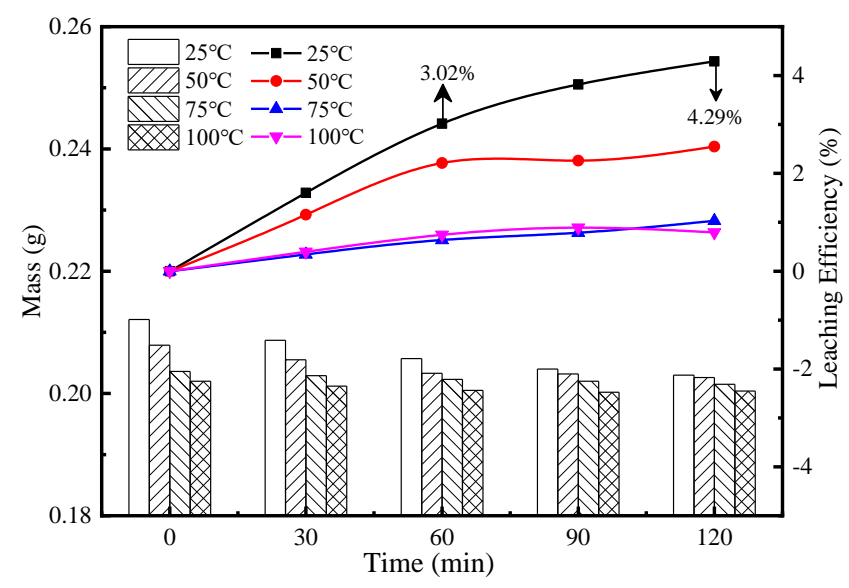

Figure 7. Influence of time and temperatures on copper leaching of $\mathrm{BmimCl}$

As the explanation for Figure 6 illustrated. Correspondingly, an appropriate leaching temperature is required as a solution for $[\mathrm{Bmim}][\mathrm{Cl}]$.

\subsection{Influence of current on copper recovery}

It's seen from Figure 6 that the inflection point occurs during the entire reaction phase for the copper recovery rate. Initially, electricity is increased and the copper recovery effect is evident. When the current is increased from $0.4 \mathrm{~A}$ to $0.5 \mathrm{~A}$, the copper recovery has increased around from $25 \%$ to $71 \%$. The amount of electricity increased continuously and the recovery rate of copper decreased to $50.01 \%$ at $1.0 \mathrm{~A}$. The recovery rate of copper was still improved in this time frame relative to the initial.

On the other hand, at the highest point of inflection, current efficiency reached about $85 \%$ while the current is $0.5 \mathrm{~A}$. Continue to boost the current level to $1.0 \mathrm{~A}$ which results the reduction in current performance around $35 \%$. The low current power $0.4 \mathrm{~A}$ demonstrated a current efficiency of $46 \%$ and the current efficiency is not increased by the high electricity.

According to the low electricity calculation, a large number of useful electrons are increased at a lower current value. The current increase promotes the reaction, which increases the recovery rate of metal copper and the whole process.

However, if the amount of electricity continues to rise, the current is extended. The voltage corresponding to the entire electrolytic cell is also increased, thereby speeding up the electrolytic recovery of copper and facilitating deposition. The solution's concentration is considerably reduced and the cations are essentially filled in the cathode chamber in the whole electrolyte, which results in more unsuccessful side reactions because of the hydrogen evolution reaction. Other metals will also deposit in the electrolyte along with the metal copper that affect the rate of recovery of metallic copper. It also decreases electrical energy usage in the electrolysis reaction.

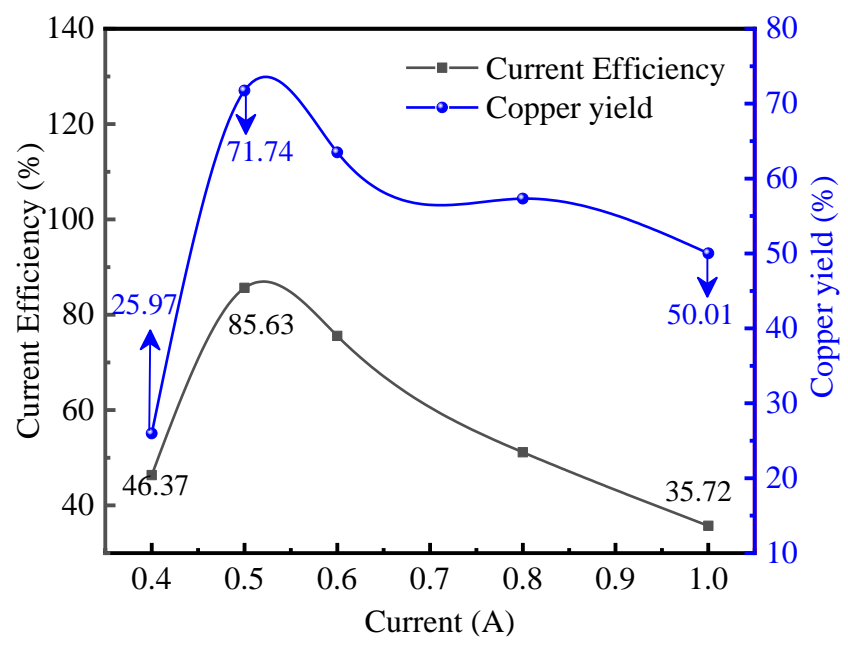

Figure 8. Influence of current magnitude on copper recovery and current efficiency

\subsection{Slurry electrolysis copper recovery with ionic liquid} (BmimPF $)$

Table 1 displays the copper electrodeposition experimental parameters in $\mathrm{BmimPF}_{6}-\mathrm{Cu}\left(\mathrm{PF}_{6}\right)_{2}$ ionic liquid solution.

Table 1. Copper electrodeposition experimental parameters

\begin{tabular}{cccc}
\hline $\begin{array}{c}\text { Current } \\
\text { intensity (A) }\end{array}$ & Time (h) & $\begin{array}{c}\text { Temperature } \\
\left({ }^{\circ} \mathrm{C}\right)\end{array}$ & $\begin{array}{c}\text { Copper molarity } \\
(\mathrm{mol} / \mathrm{L})\end{array}$ \\
\hline 0.5 & 10 & 25 & 0.08 \\
\hline 0.5 & 10 & 25 & 0.15 \\
\hline 0.5 & 10 & 25 & 0.19 \\
\hline 0.5 & 10 & 25 & 0.23 \\
\hline 0.5 & 10 & 25 & 0.32 \\
\hline
\end{tabular}

Figure 9 shows influence of the copper molar concentration on the recovery of copper and ionic liquid solution of $\mathrm{BmimPF}_{6}-\mathrm{Cu}\left(\mathrm{PF}_{6}\right)_{2}$ current efficiency. Recovery of copper rose from $61 \%$ to $85 \%$, when copper molarity concentration enhanced $0.08-0.23 \mathrm{~mol} / \mathrm{L}$. With the copper molarity continuously rising upto $0.32 \mathrm{~mol} / \mathrm{L}$ then copper recovery rate dropped at $84 \%$. Similarly, current productivity improved from $53 \%$ to $64 \%$ as the molar copper concentration augmented 0.08-0.19 mol/L, which was eventually improved $71 \%$ as the incessant rise in the concentration of copper molarity to $0.32 \mathrm{~mol} / \mathrm{L}$.

Copper concentrations increase in solution of ionic liquid would rise current cathode diffusion which leading towards cathode copper electrolysis. This will increase the copper recovery and current productivity by increasing copper concentration. 


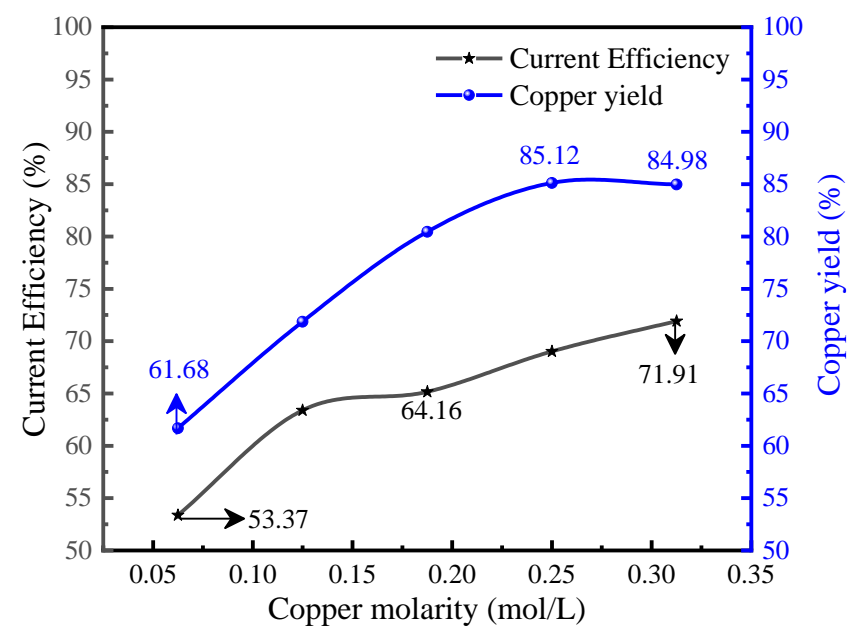

Figure 9. Influence of the concentration of copper molarity on current and copper yield

\section{Conclusions}

$[\mathrm{Bmim}]\left[\mathrm{BF}_{6}\right]$ and $[\mathrm{Emim}][\mathrm{Cl}]$ ionic liquids might be chosen as excellent and appropriate solvent, which increased the leaching efficiency of copper under appropriate effective circumstances as solution for the influence of leaching temperature and time. Where concentration of copper molarity is $0.23 \mathrm{~mol} / \mathrm{L}$ in $\mathrm{BmimPF}_{6}-\mathrm{Cu}_{(}\left(\mathrm{PF}_{6}\right)_{2}$ ionic liquid solution, as theoretical copper recovery efficiency $85 \%$ has been achieved with a current efficiency of $69 \%$.

\section{Conflict of interest}

The authors declare that there is no conflict of interest regarding the publication of this article.

\section{Acknowledgment}

This research was completed with the support of the National Natural Science Foundation of China (Grant No.51574238) and the University Student Innovation Training Program of China (Grant No.20181030).

\section{References}

Adamo I.D., Ferella F., Gastaldi M., Maggiore F., Rosa P. and Terzi S. (2019), Resources, Conservation \& Recycling Towards sustainable recycling processes: Wasted printed circuit boards as a source of economic opportunities, Resources, Conservation \& Recycling, 149(June), 455-467. https://doi.org/10.1016/j.resconrec.2019.06.012.

Chen M., Huang J., Ogunseitan O.A., Zhu N. and Wang Y. (2015), Comparative study on copper leaching from waste printed circuit boards by typical ionic liquid acids, Waste Management, 41, 142-147. https://doi.org/10.1016/ j.wasman.2015.03.037.

Choubey P.K., Panda R., Jha M.K., Lee J. and Pathak D.D. (2015), Recovery of copper and recycling of acid from the leach liquor of discarded Printed Circuit Boards (PCBs). Separation and Purification Technology, 156, 269-275. https://doi.org/10.1016/j.seppur.2015.10.012.

Chu Y., Chen M., Chen S., Wang B., Fu K. and Chen H. (2015), Micro-copper powders recovered from waste printed circuit boards by electrolysis. Hydrometallurgy, 156, 152-157. https://doi.org/10.1016/j.hydromet.2015.06.006.

Delcea C., Crăciun L., Ioanăș C., Ferruzzi G. and Cotfas L.-A. (2020), Determinants of Individuals' E-Waste Recycling
Decision: A Case Study from Romania. Sustainability, 12(7), 2753. https://doi.org/10.3390/su12072753.

Gu F., Summers P.A. and Hall P. (2019). Recovering materials from waste mobile phones: Recent technological developments. Journal of Cleaner Production, 237, 117657. https://doi.org/10.1016/j.jclepro.2019.117657.

Holgersson S., Steenari B.-M., Björkman M. and Cullbrand K. (2018), Analysis of the metal content of small-size Waste Electric and Electronic Equipment (WEEE) printed circuit boards-part 1: Internet routers, mobile phones and smartphones. Resources, Conservation and Recycling, 133, 300-308. https://doi.org/10.1016/j.resconrec.2017.02.011.

Li F., Chen M., Shu J., Shirvani M., Li Y., Sun Z., Sun S., Xu Z., Fu K. and Chen S. (2019), Copper and gold recovery from CPU sockets by one-step slurry electrolysis. Journal of Cleaner Production, 213, 673-679. https://doi.org/ 10.1016/j.jclepro.2018.12.161.

Miner K.J., Rampedi I.T., Ifegbesan A.P. and Machete F. (2020), Survey on Household Awareness and Willingness to Participate in E-Waste Management in Jos, Plateau State, Nigeria. Sustainability, 12(3), 1047. https://doi.org/ 10.3390/su12031047.

Muhammad Tariq S., Zhan H., Yang J., Tang S., Tao Y. and Liu B. (2020), A review on determination of heavy metal ions in wastewater using ionic liquids. 10(4), 115-124.

Qiu R., Lin M., Ruan J., Fu Y., Hu J., Deng M., Tang Y. and Qiu R. (2020), Recovering full metallic resources from waste printed circuit boards: A refined review. Journal of Cleaner Production, 244, 118690. https://doi.org/10.1016/ j.jclepro.2019.118690.

Sarwar M.T., Hanhui Z. and Jiaxin Y. (2020). Formative of metal contents in electronic waste mobile phone circuit boards. International Journal of Ecosystems and Ecology Science, 10(1), 203-208.

Singh S.K. and Savoy A.W. (2020), lonic liquids synthesis and applications: An overview. Journal of Molecular Liquids, 297, 112038. https://doi.org/10.1016/j.molliq.2019.112038.

Sun Z.H.I., Xiao Y., Sietsma J., Agterhuis H., Visser G. and Yang Y. (2015), Selective copper recovery from complex mixtures of end-of-life electronic products with ammonia-based solution. Hydrometallurgy, 152, 91-99. https://doi.org/ 10.1016/j.hydromet.2014.12.013.

Yang D., Chu Y., Wang J., Chen M., Shu J., Xiu F., Xu Z., Sun S. and Chen S. (2018), Completely separating metals and nonmetals from waste printed circuit boards by slurry electrolysis. Separation and Purification Technology, 205, 302-307. https://doi.org/10.1016/j.seppur.2018.04.069.

Zhang D., Dong L., Li Y., Wu Y., Ma Y. and Yang B. (2018), Copper leaching from waste printed circuit boards using typical acidic ionic liquids recovery of e-wastes' surplus value. Waste Management, 78, 191-197. https://doi.org/10.1016/j.wasman.2018.05.036.

Zhang Y., Chen M., Tan Q., Wang B. and Chen S. (2018). Recovery of copper from WPCBs using slurry electrolysis with ionic liquid $\left[\mathrm{BSO}_{3} \mathrm{HPy}\right] \cdot \mathrm{HSO}_{4}$. Hydrometallurgy, 175, 150-154. https://doi.org/10.1016/j.hydromet.2017.11.004.

Zhu P., Chen Y., Wang L.Y., Qian G.Y., Zhou M. and Zhou J. (2012), A new technology for separation and recovery of materials from waste printed circuit boards by dissolving bromine epoxy resins using ionic liquid. Journal of Hazardous Materials, 239-240, 270-278. https://doi.org/10.1016/j.jhazmat.2012.08.071. 